\title{
Transferência de imunidade passiva (TIP) e dinâmica de anticorpos específicos em bezerros naturalmente expostos para as viroses respiratórias
}

\author{
[Passive immune transfer (PIT) and dynamics of specific antibodies in calves naturally \\ exposed to the respiratory viruses] \\ B.T. Silva ${ }^{1}$, C.C. Baccili ${ }^{1}$, A. Henklein ${ }^{1}$, P.L. Oliveira ${ }^{1}$, S.M.F.N. Oliveira ${ }^{1}$, \\ N.M. Sobreira 1 , C.P. Ribeiro², V. Gomes ${ }^{1}$ \\ 1Universidade de São Paulo - São Paulo, SP \\ ${ }^{2}$ Instituto Biológico - São Paulo, SP
}

\begin{abstract}
RESUMO
Esta pesquisa avaliou a TIP e a dinâmica de anticorpos (ACs) específicos em bezerros naturalmente expostos aos agentes causadores da doença respiratória bovina (DRB). Foram selecionados 19 bezerros Holandeses alimentados com colostro proveniente de doadoras vacinadas para DRB. Amostras de soro foram obtidas antes e após a ingestão do colostro (48h) para a soroneutralização (SN). Os valores médios $\left(\log _{2}\right)$ detectados após colostragem foram de 11,5 $\pm 1,6$ (BVDV), 8,8 $\pm 1,3$ (BoHV-1), 5,5 $\pm 1,6$ (BRSV) e $8,4 \pm 1,5$ (BPIV-3). Cinco bezerros foram criados do nascimento aos 240 dias de vida, observando-se decréscimo nos títulos de ACs para BVDV, BoHV-1 e BPIV-3 ao longo do tempo ( $\mathrm{P} \leq 0,001)$. As taxas de infecções detectadas entre o D14 e o D240 foram de 40\% (2/5), $20 \%$ (1/5), $80 \%$ (4/5), e $60 \%$ (3/5), respectivamente, para BVDV, BoHV-1, BRSV e BPIV-3. A maioria dos bezerros manifestou broncopneumonia após as infecções virais. Os bezerros apresentaram ACs para todas as viroses às 48 horas de vida, porém os títulos adquiridos para o BRSV foram baixos. A susceptibilidade para as infecções variou de acordo com os níveis e a duração dos títulos de ACs maternos.
\end{abstract}

Palavras-chave: colostro, vírus da diarreia viral bovina (BVDV), herpesvírus bovino tipo 1 (BoHV-1), vírus respiratório sincicial bovino (BRSV), vírus da parainfluenza bovina tipo 3 (BPIV-3)

\begin{abstract}
This research evaluated the PIT and the dynamics of specific antibody (Ab) for calves naturally exposed to the viral agents involved in Bovine Respiratory Disease (BRD). Nineteen Holstein calves fed colostrum from vaccinated donors for DRB. Serum samples were obtained before and after colostrum intake (48h) for serum neutralization $(S N)$. Mean values $\left(\log _{2}\right)$ detected after colostrum feeding were $11.5 \pm 1.6$ $(B V D V), 8.8 \pm 1.3$ (BoHV-1) $5.5 \pm 1.6$ (BRSV) and $8.4 \pm 1.5$ (BPIV-3). Five calves were raised from birth to 240 days of life and presented a decrease in Ab titers for BVDV, BoHV-1 and BPIV-3 over time ( $P \leq$ 0.001). Infection rates from D14 to D240 were of 40\% (2/5), $20 \%$ (1/5), 80\% (4/5) and 60\% (3/5), respectively for BVDV, BoHV-1, BRSV and BPIV-3. Most of the calves presented bronchopneumonia after seroconversion to the virus. Calves presented $A b$ for all viruses at 48 hours of life, however BRSV Ab titer were low. Levels and persistence of maternal antibody titers determined the susceptibility to viral infections.
\end{abstract}

Keywords: colostrum, bovine viral diarrhea virus (BVDV), bovine alphaherpesvirus type 1 (BoHV-1), bovine syncytial virus (BRSV), bovine parainfluenza virus type 3 (BPIV-3)

Recebido em 3 de outubro de 2016

Aceito em 1 de fevereiro de 2018

E-mail: brunotoledovet@hotmail.com 


\section{INTRODUÇÃO}

O perfil do sistema imune dos recém-nascidos é determinado pela barreira fisiológica representada pela placenta bovina do tipo sinepteliocorial, que propicia ambiente uterino estéril por impedir a passagem de macromoléculas (Chucri et al., 2010). Em contrapartida, os bezerros nascem com sistema imune imaturo e agamablobulinêmico. O desenvolvimento do sistema imune ocorre gradualmente, do nascimento até a puberdade, por sucessivas exposições aos antígenos (Chase et al., 2008).

A transferência de anticorpos da mãe ao recémnascido deve ser garantida por meio da ingestão de colostro de boa qualidade (teores de $\mathrm{IgG} \geq 5.000 \mathrm{mg} / \mathrm{dL}$ ), em um volume mínimo equivalente a $8-10 \%$ de peso vivo do bezerro, em um período máximo de 18-24 horas (h) pósnascimento (p.n.). $\mathrm{O}$ monitoramento da transferência de imunidade passiva tem sido avaliada pela proteína sérica total $(\geq 5,2 \mathrm{~g} / \mathrm{dL})$ e/ou pela concentração de $\operatorname{IgG}(\geq 1.000 \mathrm{mg} / \mathrm{dL})$ às $48 \mathrm{~h}$ de vida (Godden, 2008), entretanto essas avaliações não permitem identificar a especificidade desses anticorpos para as viroses respiratórias.

ACs específicos são transferidos para os bezerros após a ingestão do colostro, desde que as vacas tenham sido previamente expostas às viroses respiratórias (Mechor et al., 1987; Bolin e Ridpath, 1995). No Brasil existem estudos avaliando a transferência de ACs específicos apenas para o BoHV-1 (Hübner et al., 1996; Moreira et al., 2001; Gatti et al., 2010) e BVDV (Gomes et al., 2014), no entanto nenhuma dessas pesquisas abordou a transferência e dinâmica de anticorpos para as quatro principais viroses respiratórias.

A duração dos anticorpos maternos está diretamente relacionada com a quantidade de imunoglobulinas ingeridas e absorvidas a partir de colostro (Fulton et al., 2004). Elevados títulos de ACs maternos neutralizantes impedem que os agentes virais alcancem os órgãos-alvo, em contrapartida bloqueiam o desenvolvimento de resposta imune ativa por exposição natural ou vacinação (Ellis et al., 2001).
O conhecimento da dinâmica de anticorpos específicos é fundamental para a deteç̧ão dos períodos de susceptibilidade para as infecções virais envolvidas na DRB e para a elaboração de protocolo vacinal. Diante disso, o objetivo da presente pesquisa foi avaliar a transferência de imunidade passiva, assim como a dinâmica de anticorpos específicos em bezerros, do nascimento aos oito meses de idade naturalmente expostos aos agentes causadores da DRB.

\section{MATERIAL E MÉTODOS}

O delineamento experimental foi aprovado pelo Comitê de Ética no Uso de Animais ( ${ }^{\circ}$ 2574) da Faculdade de Medicina Veterinária e Zootecnia (FMVZ) - Universidade de São Paulo (USP). Assim, o presente estudo foi realizado de junho de 2013 a maio de 2015, em fazenda comercial localizada na cidade de Araras $\left(22^{\circ} 10^{\prime} \mathrm{S}, 47^{\circ}\right.$ $\left.15^{\prime} \mathrm{W}\right)$, São Paulo - Brasil.

As vacas doadoras de colostro eram imunizadas com vacina comercial (Cattle Master Gold FP5+L5 ${ }^{\circledR}$, Zoetis, São Paulo - SP, Brasil), contendo estirpes de BVDV do tipo 1a (5960) e do tipo 2a (53637) inativadas; BoHV-1 (Cooper) e BPIV-3 (RLB 103) vivos/termossensíveis; BRSV (375) vivo/atenuado, além de Leptospira canicola, L. grippotyphosa, L. hardjo, $L$. icterohaemorrhagiae e L. pomona inativadas, associadas a Quil A, colesterol e Amphigen como adjuvantes. A fazenda iniciava a primovacinação em bezerras com 120 dias de vida e realizava reforço 30 dias após a primeira dose. Em seguida, os animais eram submetidos a revacinações semestrais, realizadas nos meses de abril e outubro.

A triagem do colostro foi realizada após a primeira ordenha das doadoras, com o auxílio de colostrômetro (IgG $\geq 5.000 \mathrm{mg} / \mathrm{dL}$ ) e refratrômetro Brix (21 a 32\%). O colostro foi identificado e congelado a $-20^{\circ} \mathrm{C}$, em garrafas plásticas com capacidade para dois litros, que foram previamente limpas e desinfetadas.

As vacas prenhas foram transferidas e mantidas em galpão maternidade, com camas de areia individuais e cross-ventilation, por aproximadamente 30 dias antes do parto previsto. Os partos ocorreram no inverno de $2013(\mathrm{n}=5)$, verão de $2014(\mathrm{n}=4)$, primavera de $2014(n=5)$ e verão de $2014(n=7)$. 
Foram selecionados 21 bezerros machos da raça Holandesa, oriundos de partos eutócicos. A vitalidade dos animais foi avaliada utilizando-se o teste APGAR, conforme descrito por Vannucchi et al. (2015). Após colostragem, amostras de soro dos bezerros foram coletadas para SN, realizada de acordo com OIE (2016) (detalhada abaixo), e para análise da transcriptase reversa, seguida de reação em cadeia da polimerase (RT-PCR) para exclusão de infecções fetais por BVDV, conforme descrito por Weinstock et al. (2001). Seguindo esses critérios, $2 / 21$ bezerros foram descartados porque se apresentaram soropositivos antes de ingerirem o colostro.

Todos os bezerros selecionados $(n=19)$ permaneceram, do nascimento aos cinco dias de vida, em área coletiva $(10 \times 5 \mathrm{~m})$ exclusivamente destinada ao experimento. $\mathrm{O}$ ambiente foi delimitado abaixo de uma área coberta, distante do rebanho, para evitar o contato com demais animais da fazenda e pessoas não autorizadas. O local da instalação era previamente higienizado com água e sabão neutro; em seguida, o ambiente era desinfetado com o uso de cal virgem. A cama utilizada era composta por feno proveniente da fazenda.

Todos os bezerros $(40-55 \mathrm{~kg}$ ) foram alimentados com um volume mínimo de quatro litros de colostro provenientes de vacas doadoras multíparas. Imediatamente após o nascimento, uma mamadeira contendo $2 \mathrm{~L}$ de colostro foi descongelada em banho-maria $\left(45-50^{\circ} \mathrm{C}\right)$, até o colostro atingir temperatura ideal de $37^{\circ} \mathrm{C}$ para alimentação do bezerro. Assim, a primeira mamada de colostro ocorreu em até três horas p.n. Uma segunda garrafa ( $2 \mathrm{~L}$ adicionais) foi descongelada imediatamente antes da segunda mamada, que ocorreu entre cinco e oito horas p.n. Uma sonda esofágica foi utilizada para alimentação de bezerros que não sugavam corretamente o bico da mamadeira.

Dentre os 19 bezerros, cinco foram selecionados e transferidos para a Clínica de Bovinos e Pequenos Ruminantes (CBPR) da FMVZ-USP, sendo distribuídos em baias individuais de aproximadamente $5 \times 5 \mathrm{~m}$. Antes da entrada dos animais, as baias eram lavadas com água, sabão neutro, e desinfetadas com hipoclorito de sódio. Após enxágue, era realizada desinfecção por meio de vassoura de fogo em paredes, chão, comedouro e bebedouros. A retirada e a reposição da cama das baias composta por maravalha eram realizadas duas vezes ao dia. $\mathrm{O}$ processo de lavagem e desinfecção era repetido a cada 30 dias.

Os bezerros foram alimentados com $6 \mathrm{~L}$ de sucedâneo lácteo (Sprayfo Violeta ${ }^{\circledR}$, Sloten, Santos - SP, Brasil) por dia, ração peletizada (Agromix $^{\circledR}$, Jaboticabal-SP, Brasil), sal mineral e água ad libitum até o desmame, realizado gradualmente ao atingirem dois meses de idade. A mochação dos animais foi realizada logo após o desmame.

Durante o período experimental, os bezerros foram acompanhados clinicamente quanto à presença de broncopneumonia por meio de escores (Poulsen e McGuirk, 2009), considerando-se os parâmetros temperatura retal, tosse, secreção ocular e nasal, e posição da orelha. A gravidade de cada parâmetro foi avaliada com uma pontuação de 0-3. Animais acometidos por broncopneumonia eram considerados quando a soma desses parâmetros fosse igual ou superior a 5 .

Amostras de soro foram obtidas dos 19 bezerros após a mamada do colostro (segundo dia p.n.) para avaliação dos títulos de anticorpos para BVDV, BoHV-1, BRSV e BPIV-3 após a colostragem. Para os cinco animais selecionados, as coletas de soro sanguíneo para soroneutralização foram realizadas nos seguintes momentos após a avaliação da colostragem: 14 (D14), 44, 74, 90, 120, 150, 180, 210 e 240 (D240) dias de vida.

A SN para BVDV, BoHV-1, BRSV e BPIV-3 foi realizada estritamente de acordo com o manual previamente estabelecido pela OIE (2016). Para tanto, foram utilizadas placas de poliestireno de 96 cavidades, utilizando-se uma diluição constante do soro em $\log _{2}$ a partir das diluições $1: 10$ (BVDV-NADL), 1:2 (BoHV-1), 1:2 (BRSV) e 1:2 (BPIV-3), tendo como diluente o meio de cultivo celular MEM (Minimum Essential Medium) contendo 1 a $2 \%$ de antibióticos. As amostras diluídas foram adicionadas em duplicatas nas cavidades das placas, nas quais se adicionaram $50 \mu \mathrm{L}$ da solução contendo $\mathrm{TCID}_{50} / 100 \mu \mathrm{L}(50 \%$ tissue culture infective doses) do respectivo vírus. Em seguida, as placas foram incubadas, por uma 
hora, para BVDV, BRSV, BPIV-3 e, por 18-24h, para BoHV-1, em estufa a $37^{\circ} \mathrm{C}$ com $5 \%$ de $\mathrm{CO}_{2}$. Após esse período, suspensão de células MDBK (Madin-Darby Bovine Kidney) foi adicionada em cada cavidade das placas. Novamente a placa foi incubada em estufa a $37^{\circ} \mathrm{C}$ com $5 \%$ de $\mathrm{CO}_{2}$, durante quatro a cinco dias. A infectividade foi indicada pelo efeito citopático (ECP) visível na monocamada celular em placas, em microscópio invertido. O título de anticorpos foi expresso como a maior diluição do soro que inibiu completamente a infectividade e, consequentemente, o ECP em ambas as cavidades de cada diluição.

A análise estatística foi realizada utilizando-se o programa estatístico SPSS $19.0 \quad$ (IBM Corporation, Armonk, NY). Inicialmente, todos os parâmetros foram convertidos para logaritmo de base $2\left(\log _{2}\right), \log _{10}$ e raiz quadrada para verificação da normalidade dos dados pelo teste de Shapiro-Wilk. Devido à grande amplitude de variação dos títulos de anticorpos para as viroses respiratórias, optou-se pela apresentação dos dados em $\log _{2}$. Os títulos de anticorpos adquiridos $48 \mathrm{~h}$ após a mamada de colostro apresentaram distribuição paramétrica e as diferenças entre os títulos foram determinadas por ANOVA one-way, sendo o ajuste de Bonferroni utilizado como post-hoc para comparações múltiplas $(\mathrm{P} \leq 0,008)$. A análise no tempo entre o D14 e o D240 foi realizada pela ANOVA de medidas repetidas, seguida pelo ajuste de Bonferroni como post-hoc. A taxa de infecção ativa foi baseada na proporção de animais que soroconverteram (tiveram um aumento de, pelo menos, quatro vezes ou mais nos títulos de anticorpos) (Martin e Bohac, 1989).

\section{RESULTADOS}

A transferência de anticorpos para as viroses após $48 \mathrm{~h}$ da ingestão de colostro foi observada em todos os bezerros deste estudo $(n=19)$. Os valores médios $\left(\log _{2}\right)$ detectados foram de $11,5 \pm 1,6, \quad 8,8 \pm 1,3, \quad 5,5 \pm 1,6$ e $8,4 \pm 1,5$, respectivamente, para BVDV, BoHV-1, BRSV e BPIV-3.

Os títulos obtidos para as viroses respiratórias após a ingestão do colostro foram diferentes entre si $(\mathrm{P}<0,001)$. O teste de comparações múltiplas (post-hoc) permitiu identificar diferenças significativas de BVDV em relação às demais viroses $(\mathrm{P}<0,001)$, BRSV versus $\mathrm{BPIV}-3$ $(\mathrm{P}<0,001)$ e BoHV-1 versus $\mathrm{BRSV}(\mathrm{P}<0,001)$. Não houve diferença entre os títulos médios de BoHV-1 e BPIV-3 (P=1,00) (Fig. 1).

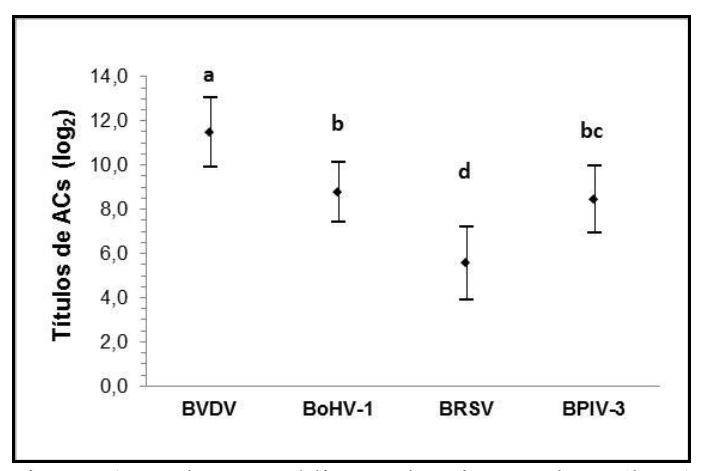

Figura 1. Valores médios e desvios-padrão $\left(\log _{2}\right)$ dos títulos de anticorpos maternos específicos adquiridos 48 horas após ingestão de colostro em 19 bezerros Holandeses. Símbolos diferentes indicam quais viroses diferem entre si pelo ajuste de Bonferroni $(\mathrm{P} \leq 0,008)$.

Entre os 19 bezerros inicialmente selecionados nesta pesquisa, cinco $(n=5)$ foram avaliados quanto à dinâmica dos anticorpos maternos dos 14 aos 240 dias de vida.

A ANOVA de medidas repetidas permitiu demonstrar diferenças dos ACs entre os momentos D14-D240 para $\operatorname{BVDV}[\mathrm{F}(8,32)=$ $17,08 ; \mathrm{P} \leq 0,001], \operatorname{BoHV}-1[\mathrm{~F}(8,32)=17,36$; $\mathrm{P} \leq 0,001]$ e BPIV-3 $[\mathrm{F}(8,32)=17,60 ; \mathrm{P} \leq 0,001]$. Contudo, não foi possível observar efeito do tempo sobre os títulos de ACs para $\operatorname{BRSV}[\mathrm{F}(8$, $32)=0,98 ; \mathrm{P}=0,468]$, visto que a média dos títulos para essa virose se manteve estável.

A análise de comparação múltipla detectou diferenças para BVDV entre os momentos D14-D120 ( $\mathrm{P}=0,01), \quad \mathrm{D} 14-\mathrm{D} 180 \quad(\mathrm{P} \leq 0,001)$, D14-D210 ( $\mathrm{P}=0,01)$, D90-D210 $(\mathrm{P}=0,03)$ e entre D120-D210 $(\mathrm{P}=0,02)$. Para o BoHV-1, a diferença foi observada entre os momentos D14-D240 ( $\mathrm{P}=0,01)$. Essas diferenças foram em decorrência da queda nos níveis de ACs nessas viroses. Em contrapartida, o ajuste de Bonferroni não permitiu identificar entre quais momentos ocorreram as diferenças entre os ACs para BIPV3.

A análise individual dos dados permitiu a detecção de infecção ativa pelo aumento dos 
títulos de ACs específicos, em pelo menos quatro vezes, em relação ao momento anterior (Martin e Bohac, 1989). As taxas de infecções detectadas nos cinco bezerros avaliados do D14 ao D240 foram de $40 \%(2 / 5), 20 \%(1 / 5), 80 \%(4 / 5)$, e $60 \%$ (3/5), respectivamente, para BVDV, BoHV1 , BRSV e BPIV-3.

O bezerro 1 apresentou infecção por BPIV-3 no D90 e por BRSV no D150 e no D240; o bezerro
2 apresentou infecção por BPIV-3 no D90 e infecção mista por BVDV e BRSV no D150; o bezerro 3 apresentou infecção por BoHV-1 no D150 e por BPIV-3 no D240; o bezerro 4 apresentou infecção por BRSV no D44 e no D180; o bezerro 5 apresentou infecção por BRSV no D44 e no D180, além de BVDV no D120 (Fig. 2).

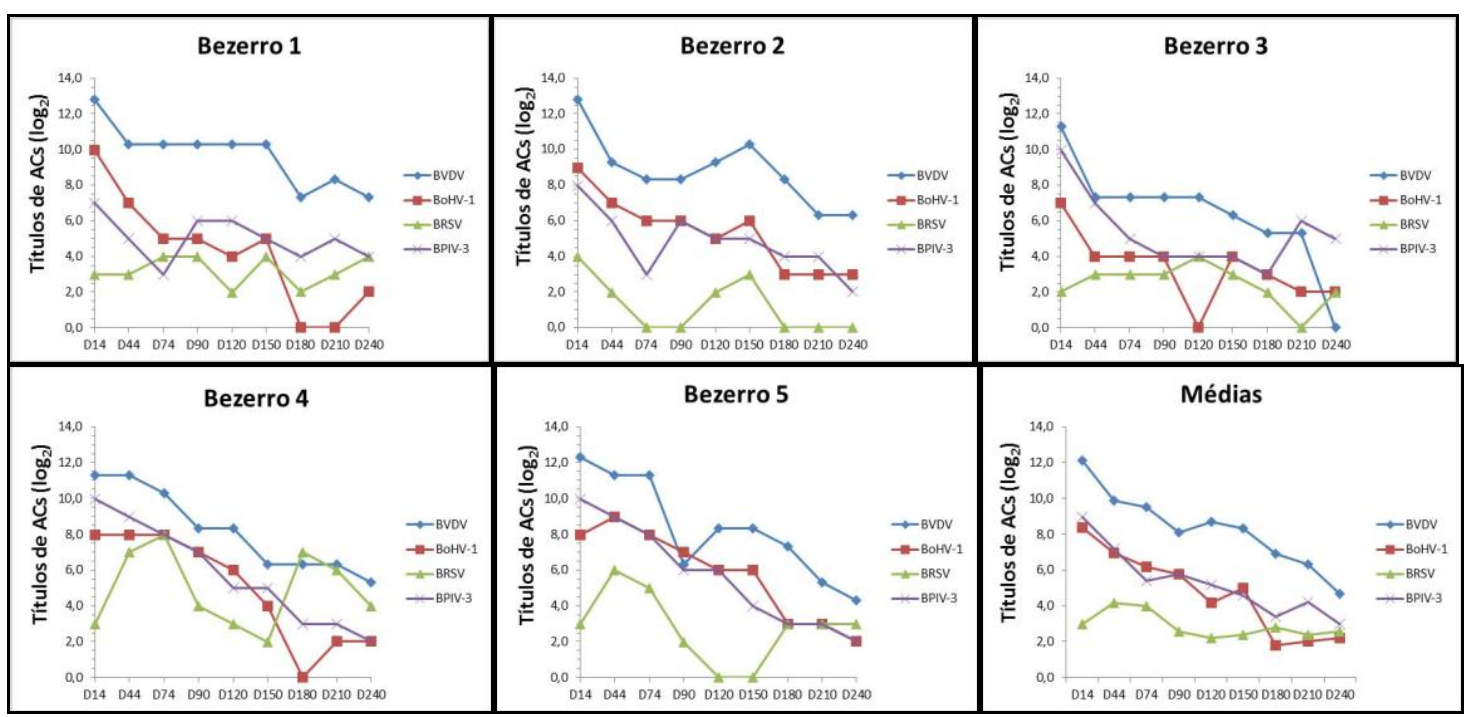

Figura 2. Comportamento individual e médias dos títulos de anticorpos (ACs) específicos para BVDV, BoHV-1, BRSV e BPIV-3 em bezerros Holandeses ( $\mathrm{n}=5)$ dos 14 aos 240 dias de vida.

A avaliação clínica permitiu identificar manifestações de broncopneumonia (escore>5) aos 80 dias de idade para os bezerros 1 e 2; aos 90 dias para o bezerro 3; e aos 135 dias para o bezerro 5. $\mathrm{O}$ bezerro 4 não apresentou manifestação clínica da doença respiratória.

\section{DISCUSSÃO}

Esta pesquisa avaliou a transferência de imunidade passiva e a dinâmica dos anticorpos específicos para as viroses respiratórias em bezerros Holandeses do nascimento aos oito meses de idade.

Os 19 bezerros soroconvertidos após a ingestão do colostro demonstraram títulos médios de ACs superiores aos valores de 7,3; 7,0 e 7,1 relatados na literatura para BVDV, BoHV-1 e BPIV-3, respectivamente (Mechor et al., 1987; Dawson, 1966; Ridpath et al., 2003). Em contrapartida, os resultados para BRSV foram praticamente semelhantes ao valor equivalente a 5,0 relatado por Belknap et al. (1991). A intensa produção e transferência de anticorpos das vacas doadoras de colostro para os bezerros provavelmente são oriundas da exposição prévia das vacas aos antígenos vacinais e da exposição natural. De acordo com o calendário sanitário da fazenda, as doadoras de colostro receberam ao menos três doses de vacina contra as viroses respiratórias até a puberdade, seguidas de reforços semestrais. Além disso, a circulação do BVDV foi comprovada, na etapa de triagem desta pesquisa, pela detecção de bezerros soropositivos para o BVDV antes da ingestão do colostro. Esses dados comprovam a circulação do vírus na fazenda.

Os títulos de anticorpos específicos para o BRSV foram menores que aqueles obtidos para BVDV, BoHV-1 e BPIV-3. Os baixos títulos de anticorpos detectados para o BRSV em relação às demais viroses podem ser justificados pela 
fraca resposta materna aos antígenos vacinais e naturais. O BRSV, assim como o vírus respiratório sincicial humano, possui a particularidade de não induzir memória imunológica de longa duração (Guzman e Taylor, 2015).

A elevada concentração de ACs maternos observada nas primeiras $48 \mathrm{~h}$ de vida, principalmente para o BVDV, contribuiu para a presença de ACs específicos ainda no D240. De acordo com Fulton et al. (2004), a duração da imunidade passiva é diretamente proporcional à quantidade de anticorpos ingeridos e absorvidos do colostro. Em contrapartida, a queda dos níveis de ACs geralmente é influenciada por infecções virais ativas ou vacinação (Kirkpatrick et al., 2008). Os cinco bezerros desta pesquisa demonstraram perfil sorológico de infecção com aumento de, pelo menos, quatro vezes nos títulos de anticorpos. Esses fatores também devem ser considerados quando comparados com dados da literatura.

A interpretação individual da dinâmica dos anticorpos específicos permitiu identificar possíveis períodos de susceptibilidade para a DRB, observando-se taxas de infecções naturais equivalentes a $40 \%$ para o BVDV, $20 \%$ para o BoHV-1, $80 \%$ para o BRSV e $60 \%$ para o BPIV3. O agente viral mais frequente foi o BRSV, assim como relatado por Sponchiado (2014).

A transmissão viral por esses agentes ocorre preferencialmente pelo contato direto entre $o$ animal infectado e o susceptível, pelas secreções respiratórias, oculares e por aerossóis (Gorden e Plummer, 2010). Neste estudo, a transmissão das viroses pode ser explicada pelo manejo adotado na criação dos bezerros durante o período experimental. Apesar do isolamento destes em baias específicas, os funcionários responsáveis pela alimentação e limpeza do ambiente hospitalar no qual as baias dos bezerros estavam inseridas podem ter contribuído para a transmissão das viroses respiratórias entre os animais internados e aqueles mantidos na área experimental.

O perfil sorológico para o BVDV demonstrou que os dois bezerros infectados naturalmente apresentavam títulos de anticorpos acima de $\log _{2}$ 4 (16), ponto de corte sinalizador de proteção descrito por Bolin e Ridpath (1995). Apenas o bezerro 5 apresentou manifestação clínica da doença respiratória aos 135 dias de idade. Evidências sugerem que o BVDV contribui para a DRB ao potencializar infecções secundárias ocasionadas por Mannheimia haemolytica e Pasteurella multocida em virtude da imunossupressão provocada (Chase et al., 2015).

A única infecção observada por BoHV-1 foi identificada no bezerro 3. Esse animal apresentava títulos abaixo dos protetores $\left(\log _{2}\right.$ 4,6) recomendados por Gungor e Ozkul (2007) desde o D44, observando-se completa metabolização dos anticorpos no D120. A manifestação clínica da DRB foi observada ao redor dos 90 dias de idade, embora a soroconversão para BoHV-1 tenha sido detectada apenas no D150. Acredita-se que a broncopneumonia nesse animal foi causada por outro agente envolvido com o complexo respiratório bovino. De acordo com Ackermann et al. (2010), a doença respiratória pode ser causada pela interação dos agentes virais, incluindo os avaliados nesta pesquisa, e bacterianos. A microbiota patogênica inclui coronavírus bovino, adenovírus bovino A-D, Mycoplasma spp., Mannheimia haemolytica, Pasteurella multocida, Histophilus somni, Arcanobacterium pyogenes e Chlamydiaceae. A infecção pelo BPIV-3 foi detectada em três bezerros no D90 (n=2) e D210 (n=1), acompanhada de manifestação do quadro clínico de broncopneumonia em dois deles, ao redor dos 90 dias de vida. Títulos protetores para o BPIV-3 não foram encontrados na literatura, porém os títulos séricos de ACs estavam próximos a 8,0 em momento anterior à infecção. A BPIV-3 é autolimitante, porém os quadros infecciosos podem ser complicados por coinfecções com outros vírus respiratórios e bactérias (Ellis, 2010).

A infecção pelo BRSV foi precoce em dois bezerros (4 e 5) aos 44 dias de vida, provavelmente pelos baixos títulos de anticorpos maternos transferidos pela mamada de colostro. É válido ressaltar que os bezerros já apresentavam títulos de anticorpos maternos abaixo dos protetores $\left(\log _{2} 6\right)$ desde as $48 \mathrm{~h}$ de vida (Windeyer et al., 2015). Primoinfecção também foi detectada nos bezerros 1 e 2 no D150. Nenhum dos bezerros apresentou quadro clínico compatível com broncopneumonia durante a primoinfecção. Bezerros neonatos 
apresentam menor quantidade de neutrófilos e menor produção de TNF- $\alpha$ nos pulmões, fato que poderia justificar a ausência de manifestações clínicas associadas à primoinfecção por BRSV (Antonis et al., 2010). A reinfecção pelo BRSV foi observada em todos os bezerros primoinfectados em momentos anteriores, exceto no bezerro 2. A reinfecção pode ser justificada pelo efeito supressor dos anticorpos maternos sobre o sistema imune ativo dos bezerros, gerando baixa memória imunológica e produção de anticorpos (Kimman et al., 1987).

Apesar das infecções naturais observadas ao longo do estudo, as médias dos ACs para BVDV, BoHV-1 e BPIV-3 mantiveram-se decrescentes ao longo do estudo. No entanto, o número amostral reduzido e a alta taxa de infecção/reinfecção para o BRSV permitiram que a média dos títulos específicos a esse agente se mantivesse estável.

Esta pesquisa também demonstrou infecções sucessivas por diferentes agentes virais. A ocorrência de forma associada de BVDV, BoHV-1, BRSV e BPIV-3 foi demonstrada por Sponchiado (2014). Essa pesquisadora identificou maior prevalência de associação entre BPIV-3 e BRSV $(37,1 \%$ - 265/714 das amostras), seguida de BVDV, BPIV-3 e BRSV $(19,5 \%)$ e a associação dos quatro vírus estudados $(13,4 \%)$.

O presente estudo mensurou apenas os títulos de anticorpos séricos para as viroses respiratórias. É importante ressaltar que a proteção contra o BRSV e o BPIV-3 é mais dependente dos níveis de $\operatorname{IgA}$ específica na mucosa respiratória que os títulos séricos de anticorpos (Ellis, 2010; Guzman e Taylor, 2015).

Diante das condições apresentadas neste estudo, pôde-se concluir que a susceptibilidade à DRB está diretamente relacionada com os níveis e a persistência dos ACs maternos adquiridos ao nascimento.

\section{CONCLUSÕES}

Os bezerros apresentaram anticorpos para todas as viroses após a ingestão do colostro, porém os títulos adquiridos para o BRSV foram baixos, apesar do intenso esquema de vacinação ao qual as vacas doadoras de colostro eram submetidas.
Esse fato justifica a precocidade das infecções detectadas para o BRSV. A susceptibilidade para as demais viroses variou de acordo com os níveis e a duração dos títulos de anticorpos maternos. Esses dados podem colaborar com a elaboração do calendário sanitário na criação de bezerras.

\section{AGRADECIMENTOS}

Os autores são gratos a todos os membros da Fazenda Colorado e aos demais participantes deste estudo. Agradecem pelo suporte financeiro viabilizado pela Fundação de Amparo à Pesquisa do Estado de São Paulo (São Paulo, Brasil; número do Projeto 2012/02129-8) e à empresa Zoetis, além de bolsa de estudos concedida pelo Conselho Nacional de Desenvolvimento Científico e Tecnológico (CNPq).

\section{REFERÊNCIAS}

ACKERMANN, M.R.; DERSCHEID, R.; ROTH, J.A. Innate immunology of bovine respiratory disease. Vet. Clin. N. Am. Food Anim. Pract., v.26, p.215-228, 2010.

ANTONIS, A.F.; JONG, M.C.; VAN DER POEL, W.H. et al. Age-dependent differences in the pathogenesis of bovine respiratory syncytial virus infections related to the development of natural immunocompetence. J. Gen. Virol., v.91, p.2497-2506, 2010

BELKNAP, E.B.; BAKER, J.C.; PATTERSON, J.S. et al. The role of passive immunity in bovine respiratory syncytial virus-infected calves. $J$. Infect. Dis., v.163, p.470-476, 1991.

BOLIN, S.R.; RIDPATH, J.F. Assessment of protection from systemic infection or disease afforded by low to intermediate titers of passively acquired neutralizing antibody against bovine viral diarrhea virus in calves. Am. J. Vet. Res., v.56, p.755-759, 1995.

CHASE, C.C.L.; HURLEY, D.J.; REBER, A.J. Neonatal immune development in the calf and its impact on vaccine response. Vet. Clin. N. Am. Food Anim. Pract., v.24, p.87-104, 2008.

CHASE, C.C.L.; THAKUR, N.; DARWEESH, M.F. et al. Immune response to bovine viral diarrhea virus-looking at newly defined targets. Anim. Health Res. Rev., v.16, p.4-14, 2015. 
CHUCRI, T.M.; MONTEIRO, J.M.; LIMA, A.R. et al. A review of immune transfer by the placenta. J. Reprod. Immunol., v.87, p.14-20, 2010.

DAWSON, P.S. Persistence of maternal antibodies to parainfluenza 3 virus. J. Comp. Pathol., v.76, p.373-378, 1966.

ELLIS, J.; WEST, K.; CORTESE, V. et al. Effect of maternal antibodies on induction and persistence of vaccine-induced immune responses against bovine viral diarrhea virus type II in young calves. J. Am. Vet. Med. Assoc., v.219, p.351-356, 2001.

ELLIS, J.A. Bovine parainfluenza-3 virus. Vet. Clin. N. Am. Food Anim. Pract., v.26, p.575-93, 2010.

FULTON, R.W.; BRIGGS, R.E.; PAYTON, M.E. et al. Maternally derived humoral immunity to bovine viral diarrhea virus (BVDV) 1a, BVDV1b, BVDV2, bovine herpesvirus-1, parainfluenza-3 virus bovine respiratory syncytial virus, Mannheimia haemolytica and Pasteurella multocida in beef calves, antibody decline by half-life studies and effect on response to vaccination. Vaccine, v.22, p.643649, 2004.

GATTI, S.P.; AFFONSO, I.B.; DIAS, F.C. et al. Títulos de anticorpos antiherpesvírus bovino tipo 1 (BoHV-1) de bezerras em três rebanhos leiteiros do estado de São Paulo, Brasil. Ars Vet., v.26, p.147-152, 2010.

GODDEN, S. Colostrum management for dairy calves. Vet. Clin. N. Am. Food Anim. Pract., v.24, p.19-39, 2008.

GOMES, V.; BACCILI, C.C.; SILVA, C.P.C. et al. Humoral immunity assessment in calves born to cows immunized with inactivated vaccine for bovine herpesvirus 1 and bovine viral diarrhea virus. Acta Sci. Vet., v.42, p.1239, 2014.

GORDEN, P.J.; PLUMMER, P. Control, management, and prevention of bovine respiratory disease in dairy calves and cows. Vet. Clin. N. Am. Food Anim. Pract., v.26, p.243-259, 2010.

GUNGOR, A.B.; OZKUL, A. Dynamics of natural bovine herpesvirus-1 (BoHV-1) infection in a dairy herd. Trop. Anim. Health Prod., v.39, p.13-20, 2007.
GUZMAN, E.; TAYLOR, G. Immunology of bovine respiratory syncytial virus in calves. Mol. Immunol., v.66, p.48-56, 2015.

HÜBNER, S.D.O; WEIBLEN, R.; SILVA, A.M.D. et al. Evolução da imunidade passiva contra o herpesvírus bovino tipo 1. Cienc. Rural, v.26, p.435-439, 1996.

KIMMAN, T.G.; WESTENBRINK, F.; SCHREUDER, B.E. et al. Local and systemic antibody response to bovine respiratory syncytial virus infection and reinfection in calves with and without maternal antibodies. J. Clin. Microbiol., v.25, p.1097-1106, 1987.

KIRKPATRICK, J.G.; STEP, D.L.; PAYTON, M.E. et al. Effect of age at the time of vaccination on antibody titers and feedlot performance in beef calves. J. Am. Vet. Med. Assoc., v.233, p.136-142, 2008.

MARTIN, S.W.; BOHAC, J.G. The association between serological titers in infectious bovine rhinotracheitis virus, bovine virus diarrhea virus, parainfluenza-3 virus, respiratory syncytial virus and treatment for respiratory disease in Ontario feedlot calves. Can. J. Vet. Res., v.50, p.351, 1986.

MECHOR, G.D.; ROUSSEAUX, C.G.; RADOSTITS, O.M. et al. Protection of newborn calves against fatal multisystemic infectious bovine rhinotracheitis by feeding colostrum from vaccinated cows. Can. J. Vet. Res., v.51, p.452459, 1987.

MOREIRA, S.P.G.; SAMARA, S.I.; ARITA, G.M.M. et al. Monitoração de anticorpos neutralizantes para o vírus da rinotraqueíte infecciosa bovina em bezerros. Braz. J. Vet. Res. Anim. Sci., v.38, p.127-130, 2001.

OIE World Organisation for Animal Health, manual of diagnostics tests and vaccines for terrestrial animals, 2016. Available in: <http://www.oie.int/en/international-standardsetting/terrestrial-manual/access-online/>.

Accessed in: 3 Mar. 2016.

POULSEN, K.P.; MCGUIRK, S.M. Respiratory disease of the bovine neonate. Vet. Clin. N. Am. Food Anim. Pract., v.25, p.121-137, 2009. 
RIDPATH, J.F.; NEIL, J.D.; ENDSLEY, J. et al. Effect of passive immunity on the development of a protective immune response against bovine viral diarrhea virus in calves. Am. J. Vet. Res., v.64, p.65-69, 2003.

SPONCHIADO, D. Prevalência dos principais vírus respiratórios em bovinos da raça Holandesa, no estado do Paraná. 2014. 151f. Tese (Doutorado em Medicina Veterinária) Faculdade de Medicina Veterinária e Zootecnia, Universidade Estadual Paulista, Botucatu, SP.

VANNUCCHI, C.I.; RODRIGUES, J.A.; SILVA, L.C.G. et al. Effect of dystocia and treatment with oxytocin on neonatal calf vitality and acid-base, electrolyte and haematological status. Vet. J., v.203, p.228-232, 2015.
WEINSTOCK, D.; BHUDEVI, B.; CASTRO, A.E. Single-tube single-enzyme reverse transcriptase PCR assay for detection of bovine viral diarrhea virus in pooled bovine serum. $J$. Clin. Microbiol., v.39, p.343-346, 2001.

WINDEYER, M.C.; LESLIE, K.E.; GODDEN, S.M. et al. Association of bovine respiratory disease or vaccination with serologic response in dairy heifer calves up to three months of age. Am. J. Vet. Res., v.76, p.239-245, 2015. 